\title{
Association of urine mitochondrial DNA with clinical measures of COPD in the SPIROMICS cohort
}

William Z. Zhang,,$^{1,2}$ Michelle C. Rice, ${ }^{3}$ Katherine L. Hoffman, ${ }^{4}$ Clara Oromendia, ${ }^{4}$ Igor Z. Barjaktarevic, ${ }^{5}$ J. Michael Wells, ${ }^{6}$ Annette T. Hastie, ${ }^{7}$ Wassim W. Labaki, ${ }^{8}$ Christopher B. Cooper, ${ }^{5}$ Alejandro P. Comellas, ${ }^{9}$ Gerard J. Criner, ${ }^{10}$ Jerry A. Krishnan, ${ }^{11}$ Robert Paine III, ${ }^{12}$ Nadia N. Hansel, ${ }^{13}$ Russell P. Bowler, ${ }^{14}$ R. Graham Barr, ${ }^{15}$ Stephen P. Peters, ${ }^{7}$ Prescott C. Woodruff, ${ }^{16}$ Jeffrey L. Curtis, ${ }^{8,17}$ Meilan K. Han, ${ }^{8}$ Karla V. Ballman, ${ }^{4}$ Fernando J. Martinez, ${ }^{1,2}$ Augustine M.K. Choi, ${ }^{1,2}$ Kiichi Nakahira, ${ }^{1}$ Suzanne M. Cloonan, ${ }^{1}$ Mary E. Choi, ${ }^{2,3}$ and the SPIROMICS Investigators ${ }^{18}$

'Division of Pulmonary and Critical Care Medicine, Joan and Sanford I. Weill Department of Medicine, New York, New York, USA. ${ }^{2}$ New York-Presbyterian Hospital, Weill Cornell Medicine, New York, New York, USA. ${ }^{3}$ Division of Nephrology and Hypertension, Joan and Sanford I. Weill Department of Medicine, and ${ }^{4}$ Department of Healthcare Policy and Research, Division of Biostatistics and Epidemiology, Weill Cornell Medicine, New York, New York, USA. ${ }^{5}$ Division of Pulmonary and Critical Care Medicine, UCLA Medical Center, Los Angeles, California, USA. EUniversity of Alabama at Birmingham, Birmingham, Alabama, USA. ${ }^{7}$ Pulmonary, Critical Care, Allergy, and Immunologic Medicine, Wake Forest School of Medicine, Winston-Salem, North Carolina, USA. ${ }^{8}$ Division of Pulmonary and Critical Care Medicine, University of Michigan Health System, Ann Arbor, Michigan, USA. 'Division of Pulmonary and Critical Care, University of lowa, lowa City, lowa, USA. ${ }^{10}$ Department of Thoracic Medicine and Surgery, Lewis Katz School of Medicine at Temple University, Philadelphia, Pennsylvania, USA. "Division of Pulmonary, Critical Care, Sleep and Allergy, University of Illinois College of Medicine, Chicago, Illinois, USA. ${ }^{12}$ Division of Respiratory, Critical Care, and Occupational Pulmonary Medicine, University of Utah, Salt Lake City, Utah, USA. ${ }^{13}$ Division of Pulmonary and Critical Care Medicine, Johns Hopkins University School of Medicine, Baltimore, Maryland, USA. ${ }^{14}$ Division of Pulmonary, Critical Care Medicine, National Jewish Health, Denver, Colorado, USA. ${ }^{15}$ Columbia University Medical Center, New York, New York, USA. ${ }^{16}$ Division of Pulmonary and Critical Care Medicine, UCSF, School of Medicine, San Francisco, California, USA. ${ }^{17}$ Veterans Affairs Ann Arbor Healthcare System, Ann Arbor, Michigan, USA. ${ }^{18}$ The SPIROMICS Investigators are detailed in the Acknowledgments.

Authorship note: WZZ and MCR contributed equally to this work.

Conflict of interest: See supplemental material for conflict of interest statement.

Copyright: ( 2020 , American Society for Clinical Investigation.

Submitted: October 2, 2019

Accepted: December 26, 2019

Published: February 13, 2020

Reference information: /CI Insight. 2020;5(3):e133984.

https://doi.org/10.1172/jci.

insight.133984.
BACKCROUND. Mitochondrial dysfunction, a proposed mechanism of chronic obstructive pulmonary disease (COPD) pathogenesis, is associated with the leakage of mitochondrial DNA (mtDNA), which may be detected extracellularly in various bodily fluids. Despite evidence for the increased prevalence of chronic kidney disease in COPD subjects and for mitochondrial dysfunction in the kidneys of murine COPD models, whether urine mtDNA (u-mtDNA) associates with measures of disease severity in COPD is unknown.

METHODS. Cell-free u-mtDNA, defined as copy number of mitochondrially encoded NADH dehydrogenase-1 (MTND1) gene, was measured by quantitative PCR and normalized to urine creatinine in cell-free urine samples from participants in the Subpopulations and Intermediate Outcome Measures in COPD Study (SPIROMICS) cohort. Urine albumin/creatinine ratios (UACR) were measured in the same samples. Associations between u-mtDNA, UACR, and clinical disease parameters - including $\mathrm{FEV}_{1} \%$ predicted, clinical measures of exercise tolerance, respiratory symptom burden, and chest CT measures of lung structure - were examined.

RESULTS. U-mtDNA and UACR levels were measured in never smokers $(n=64)$, smokers without airflow obstruction ( $n=109)$, participants with mild/moderate COPD $(n=142)$, and participants with severe COPD $(n=168)$. U-mtDNA was associated with increased respiratory symptom burden, especially among smokers without COPD. Significant sex differences in u-mtDNA levels were observed, with females having higher u-mtDNA levels across all study subgroups. U-mtDNA associated with worse spirometry and CT emphysema in males only and with worse respiratory symptoms in females only. Similar associations were not found with UACR. 
CONCLUSION. U-mtDNA levels may help to identify distinct clinical phenotypes and underlying pathobiological differences in males versus females with COPD.

TRIAL REGISTRATION. This study has been registered at ClinicalTrials.gov ( NCT01969344).

FUNDING. US NIH, National Heart, Lung and Blood Institute, supplemented by contributions made through the Foundation for the NIH and the COPD Foundation from AstraZeneca/ MedImmune, Bayer, Bellerophon Therapeutics, Boehringer-Ingelheim Pharmaceuticals Inc., Chiesi Farmaceutici S.p.A., Forest Research Institute Inc., GlaxoSmithKline, Grifols Therapeutics Inc., Ikaria Inc., Novartis Pharmaceuticals Corporation, Nycomed GmbH, ProterixBio, Regeneron Pharmaceuticals Inc., Sanofi, Sunovion, Takeda Pharmaceutical Company, and Theravance Biopharma and Mylan.

\section{Introduction}

Chronic obstructive pulmonary disease (COPD) is a heterogenous lung disease resulting from an abnormal inflammatory and reparative response to toxic inhalants - in particular, cigarette and biomass smoke. The marked heterogeneity of COPD manifests as distinct clinical phenotypes and trajectories, and it likely starts very early in disease pathogenesis, in smokers who have yet to develop COPD by current spirometric criteria (1). Identifying disease mechanisms or endotypes to explain the heterogeneity of COPD more clearly or to differentiate 1 patient from another is therefore of critical importance (2). The development of novel biomarkers and personalized therapies can occur only with a more nuanced understanding of the underlying biologic processes, especially at disease onset $(3,4)$.

One underlying biological mechanism that may provide insight into COPD pathogenesis and progression is mitochondrial dysfunction, which is consistently observed in cells derived from COPD subjects (5-13), as well as in experimental COPD models $(11,14)$. Such mitochondrial dysfunction is associated with the leakage of mitochondrial DNA (mtDNA) (15-19), a mitochondrial derived danger- associated molecular pattern (mtDAMP) $(20,21)$. Intracellularly, mtDNA acts as an essential second messenger that activates pathogen recognition receptors (PRRs) - in particular, the NLRP3 inflammasome and the DNA sensor cyclic GMP-AMP synthase (cGAS), eliciting a series of innate immune signaling cascades (21-24). When found extracellularly, cell-free mtDNA - which can be detected in a range of biological fluids including plasma, serum, urine, and bronchoalveolar lavage fluid (25-27) - activates neutrophils (22), vascular endothelial cells (28), and alveolar macrophages (29), perpetuating inflammatory signals or cascades. mtDNA has been proposed as a biomarker and prognostic indicator for a range of diseases and syndromes $(25,26,30-42)$. The source of this extracellular mtDNA is unknown but is assumed to arise from injured cells either in the process of cell death or repair (43). Extracellular mtDNA has not been examined for association with clinical phenotypes or outcomes in a large, well-characterized COPD cohort.

Based on the hypothesis that leakage of extracellular mtDNA is reflective of mitochondrial dysfunction in subjects with COPD, we sought to determine if extracellular mtDNA levels associate with unique COPD subgroups in the extensively characterized Subpopulations and Intermediate Outcome Measures in COPD Study (SPIROMICS). In this study, we chose to measure urine extracellular urine mtDNA (u-mtDNA) levels, as it may serve as an indicator of systemic mitochondrial damage. Additionally, recent studies from our group and others provide evidence that individuals with COPD have a higher incidence of chronic kidney disease (CKD) (44-55) and that mitochondrial dysfunction may be one of the mechanisms behind this finding (56). Specifically, we have recently shown that exposure to cigarette smoke induces mitochondrial swelling and loss of cristae in murine renal tubular epithelial cells (56), and that glomerulosclerosis and tubulointerstitial fibrosis occur more frequently in patients with COPD than in control subjects (44). U-mtDNA/creatinine ratios are higher in subjects with acute or chronic kidney injury, suggesting that u-mtDNA may offer potential as a unique biomarker for patients with kidney injury $(26,32-34,36-38,41,42)$. For comparison, we also measured urine albumin, which has an established connection with CKD and with lung function decline in COPD (44,51-54). We herein show that $\mathrm{u}-\mathrm{mtDNA}$ associates with important clinical outcomes in COPD, providing further evidence for mitochondrial dysfunction in COPD pathobiology. 


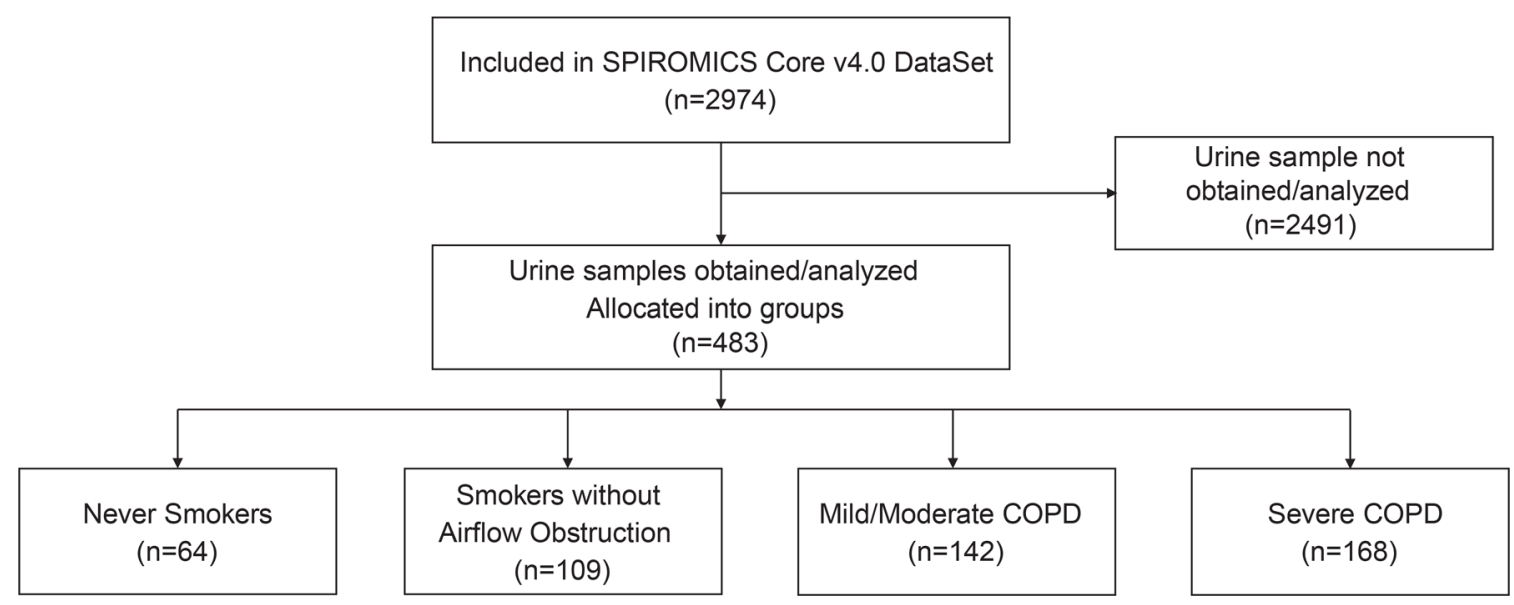

Figure 1. Flow diagrams for the participants in this SPIROMICS substudy. COPD, chronic obstructive pulmonary disease.

\section{Results}

SPIROMICS participant characteristics. Flow diagram for SPIROMICS and the characteristics of the participants for whom urine samples were analyzed are shown in Figure 1 and Table 1. Compared with participants in the overall SPIROMICS cohort, the participants in this study were less likely to be current smokers $(P<0.001)$; the severe COPD subgroup is also slightly overrepresented (Supplemental Table 1; supplemental material available online with this article; https://doi.org/10.1172/jci.insight.133984DS1). Urine albumin, creatinine, and cellfree u-mtDNA were measured in 483 participants, of which 64 were never smokers, 109 were smokers without airflow obstruction, 142 were participants with mild/moderate COPD, and 168 had severe COPD (Table 1). Compared with never smokers and smokers without airflow obstruction, participants with COPD were predominantly male and older, and in particular, participants with severe COPD had a lower BMI compared with the other subgroups. There was no difference between any of the subgroups in the rate of genitourinary conditions, which includes $\operatorname{CKD}(P=0.39$, Table 1$)$.

Urine albumin/creatinine ratio as a COPD biomarker in the SPIROMICS cohort. We first examined the relationship between urine albumin/creatinine ratio (UACR), a marker of kidney injury, and disease severity in the SPIROMICS cohort. Consistent with previous reports using different COPD cohorts (51, 53, 54, 57-59), UACR was significantly increased in subjects with mild $/$ moderate (median $=10.4 \mathrm{mg} / \mathrm{g}, P=$ 0.010 ) and severe (median $=10.2 \mathrm{mg} / \mathrm{g}, P=0.002$ ) COPD, when compared with smokers without airflow obstruction (median $=7.0 \mathrm{mg} / \mathrm{g}$; Figure $2 \mathrm{~A}$ ). This association remained significant after adjusting for smoking status, age, sex, and BMI $(\hat{\beta}=0.38[0.01,0.75], P=0.042$ for mild/moderate $\operatorname{COPD} ; \hat{\beta}=0.53$ $[0.17,0.90], P=0.004$ for severe COPD; Table 2$)$. UACR was also significantly higher in cur- rently smoking participants with COPD (median $=8.95 \mathrm{mg} / \mathrm{g}$ ) compared with participants with COPD who are not currently smoking (median $=7.0 \mathrm{mg} / \mathrm{g}, P=0.027$, Figure $2 \mathrm{~B}$ ).

Albuminuria has been associated with lung function decline in large population-based longitudinal cohort studies (54). To validate these findings, we examined the relationship between UACR levels and important clinical parameters in the SPIROMICS cohort. In SPIROMICS, UACR was inversely associated with percent predicted postbronchodilator forced expiratory volume in 1 second (FEV1 \% predicted) in unadjusted analyses $(\hat{\beta}=-0.12[-0.20,-0.03], P=0.009)$, but this association lost significance with adjustment $(\hat{\beta}=-0.08[-0.17,0.01], P=0.069)$ (Figure $2 \mathrm{C}$ and Supplemental Table 2). UACR was not significantly associated with 6-minute walk distance (6MWD) or St. George's Respiratory Questionnaire (SGRQ) score in unadjusted or adjusted analyses, but it was higher in participants with more significant respiratory symptoms, as defined by COPD Assessment Test (CAT) score $\geq 10$, an association that persisted with adjustment (unadjusted $\hat{\beta}=0.37$ [0.09, 0.65], $P=0.009$; adjusted $\hat{\beta}=0.31[0.03,0.59]$, $P=0.033$; Figure 2D; Supplemental Figure 1, A and B; Supplemental Table 2). UACR was not significantly associated with radiographic measures of emphysema in unadjusted or adjusted analyses, but it was associated with radiographic small airway disease (functional small airway disease by parametric response mapping; PRM $\left.{ }^{\mathrm{FSAD}}\right)$ in the unadjusted analyses $(\hat{\beta}=0.01[0.0008,0.02], P=0.033)$, although this was lost with adjustment (Supplemental Figure 1, C-E, and Supplemental Table 2). 
Table 1. Baseline characteristics of the urine mtDNA study population

\begin{tabular}{|c|c|c|c|c|c|}
\hline Parameter & $\begin{array}{l}\text { Never smokers } \\
\quad(n=64)\end{array}$ & $\begin{array}{l}\text { Smokers without } \\
\text { airflow obstruction } \\
\qquad(n=109)\end{array}$ & $\begin{array}{l}\text { Mild/moderate COPD } \\
\qquad(n=142)\end{array}$ & $\begin{array}{l}\text { Severe COPD } \\
\quad(n=168)\end{array}$ & $P$ value $^{A}$ \\
\hline Age, median (IQR) & $57.0(50.8-66.2)$ & $60.0(51.0-67.0)$ & $66.0(60.2-71.0)$ & $65.0(59.0-71.0)$ & $<0.001$ \\
\hline Male $N(\%)$ & $20(31.2)$ & $48(44.0)$ & $83(58.5)$ & $107(63.7)$ & $<0.001$ \\
\hline BMI, median (IQR) & $29.4(26.0-33.2)$ & $28.2(25.4-32.3)$ & $28.5(25.0-32.7)$ & $26.3(22.3-30.4)$ & $<0.001$ \\
\hline $\begin{array}{c}\text { Race } N(\%) \\
\text { American Indian } \\
\text { Asian } \\
\text { Black } \\
\text { Mixed descent } \\
\text { White }\end{array}$ & $\begin{array}{c}0(0.00) \\
1(1.56) \\
16(25.0) \\
2(3.12) \\
45(70.3)\end{array}$ & $\begin{array}{c}0(0.00) \\
1(0.93) \\
33(30.6) \\
5(4.63) \\
69(63.9)\end{array}$ & $\begin{array}{c}0(0.00) \\
4(2.82) \\
13(9.15) \\
1(0.70) \\
124(87.3)\end{array}$ & $\begin{array}{c}1(0.60) \\
2(1.20) \\
24(14.5) \\
3(1.81) \\
136(81.9)\end{array}$ & $<0.001$ \\
\hline $\begin{array}{c}\text { Current nonsmoker } N \\
(\%)\end{array}$ & $64(100)$ & $54(50.9)$ & $91(66.4)$ & $128(78.0)$ & $<0.001$ \\
\hline $\begin{array}{l}\mathrm{FEV}_{1} \% \text { predicted, } \\
\text { median (IQR) }\end{array}$ & $101(94.7-108)$ & 95.8 (86.8-105) & $70.5(61.4-77.8)$ & $33.2(26.6-43.4)$ & $<0.001$ \\
\hline
\end{tabular}

${ }^{A}$ Kruskal-Wallis test, $\chi^{2}$ test, or Fisher's exact test comparing participants within each subgroup, as appropriate. ${ }^{B}$ American Indian, Asian, Black, Native Hawaiian or Other Pacific Islander, and White. IQR, interquartile range ( $25 \%$ and $75 \%$ percentiles); FEV ${ }_{1}$, forced expiratory volume in 1 second.

$U-m t D N A$ associates with respiratory symptoms and exercise tolerance in COPD, especially in smokers with early disease. Given the prior evidence for mitochondrial dysfunction in COPD, we next investigated the potential of $\mathrm{u}$-mtDNA as a biomarker using the SPIROMICS cohort. U-mtDNA levels were similar among never smokers $\left(\right.$ median $=2.46 \times 10^{9}$ copies $\left./ g\right)$, smokers without airflow obstruction $\left(\right.$ median $=2.37 \times 10^{9}$ copies $/ g$ ), and participants with COPD (median $=2.97 \times 10^{9}$ copies $/ g$ for mild $/$ moderate COPD and $2.77 \times$ $10^{9}$ copies/g for severe COPD) in unadjusted analyses, although after adjustment, participants with both mild/moderate and severe COPD had significantly higher u-mtDNA levels than smokers without airflow obstruction $(\hat{\beta}=0.36[0.00,0.73], P=0.050$, for mild/moderate COPD; $\hat{\beta}=0.40[0.04,0.77], P=0.032$, for severe COPD) (Figure 3A and Table 3). Current smoking status did not affect u-mtDNA levels, in contrast to UACR (Figure 3B). U-mtDNA was not significantly associated with $\mathrm{FEV}_{1} \%$ predicted, in the overall study cohort or within each individual subgroup in unadjusted or adjusted analyses (Figure 3C, Supplemental Figure 2, and Table 4). Notably, u-mtDNA and UACR were significantly associated in matched participants in the SPIROMICS cohort (Supplemental Figure 3).

We next examined the relationship between $u-m t D N A$ and measures of respiratory symptom burden and exercise capacity. In contrast to UACR, u-mtDNA correlated with $6 \mathrm{MWD}(\hat{\beta}=-0.02[-0.03,-0.01], P=0.002)$ and SGRQ $(\hat{\beta}=0.01[0.006,0.01], P=0.045)$, and it was higher in participants with more severe symptoms by CAT ( $\hat{\beta}=0.36[0.08,0.64], P=0.013)$; these associations remained significant after adjustment (Figure 4, A-C, and Table 4). In subgroup analysis, these correlations were most notable among smokers without airflow obstruction, for $6 \mathrm{MWD}(\hat{\beta}=-0.04[-0.07,-0.01], P=0.004)$, SGRQ $(\hat{\beta}=0.03[0.01$, $0.04], P=0.002)$, and CAT $\geq 10(\hat{\beta}=1.09[0.48,1.70], P<0.001)$, although the relationships with 6MWD and SGRQ were no longer significant after adjustment, potentially due to a loss of power (Figure 4, D-F, and Table 4). Unadjusted u-mtDNA was not significantly associated with radiographic measures of small airway disease and emphysema; however, after adjustment for age, sex, BMI , and smoking status, u-mtDNA was significantly associated with emphysema $(\hat{\beta}=0.01[0.002,0.03], P=0.028$, for emphysema by PRM [PRM $\left.{ }^{\mathrm{EMPH}}\right] ; \hat{\beta}=0.01[0.002,0.03], P=0.028$, for percentage of low attenuation area (LAA) less than -950 Hounsfield units (HU); Supplemental Figure 4 and Supplemental Table 3).

$U$-mtDNA associates with different clinical outcomes in males and females. Despite the well-described sex differences in COPD presentation and progression (60-63), there are currently no validated biomarkers that parallel these clinical observations. In the SPIROMICS cohort, we found that u-mtDNA levels were significantly higher in female participants when compared with male participants (median $=3.94 \times 10^{9}$ copies/g vs. $2.13 \times 10^{9}$ copies $\left./ g, P<0.001\right)$ and that this difference was consistent across all subgroups, including never smokers (median $=3.56 \times 10^{9} \mathrm{copies} / \mathrm{g}$ vs. $1.82 \times 10^{9}$ copies $/ \mathrm{g}, P=0.003$ ), smokers 
A

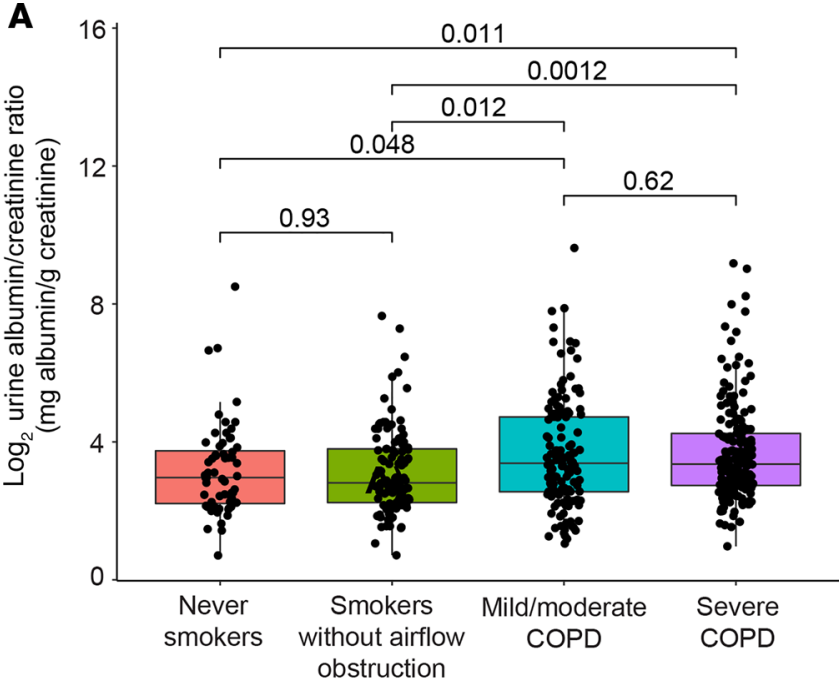

C

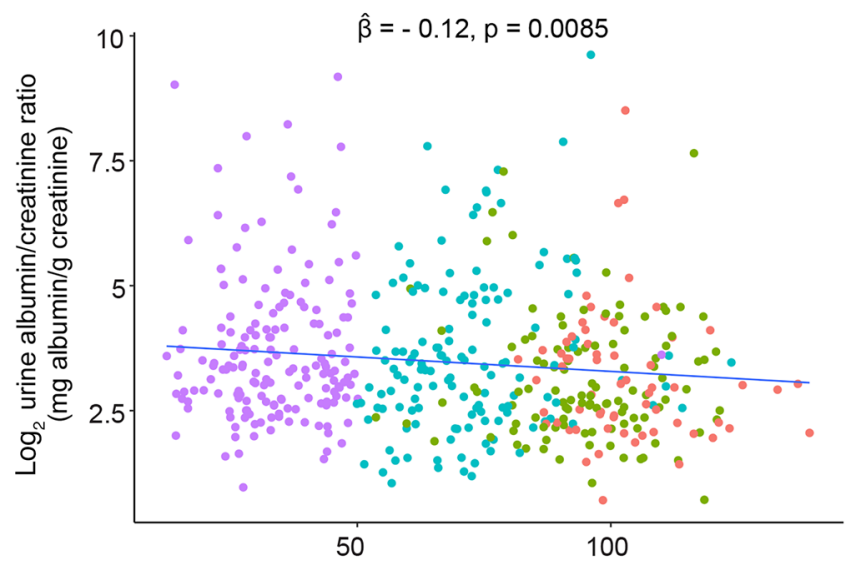

FEV $1 \%$ predicted
B
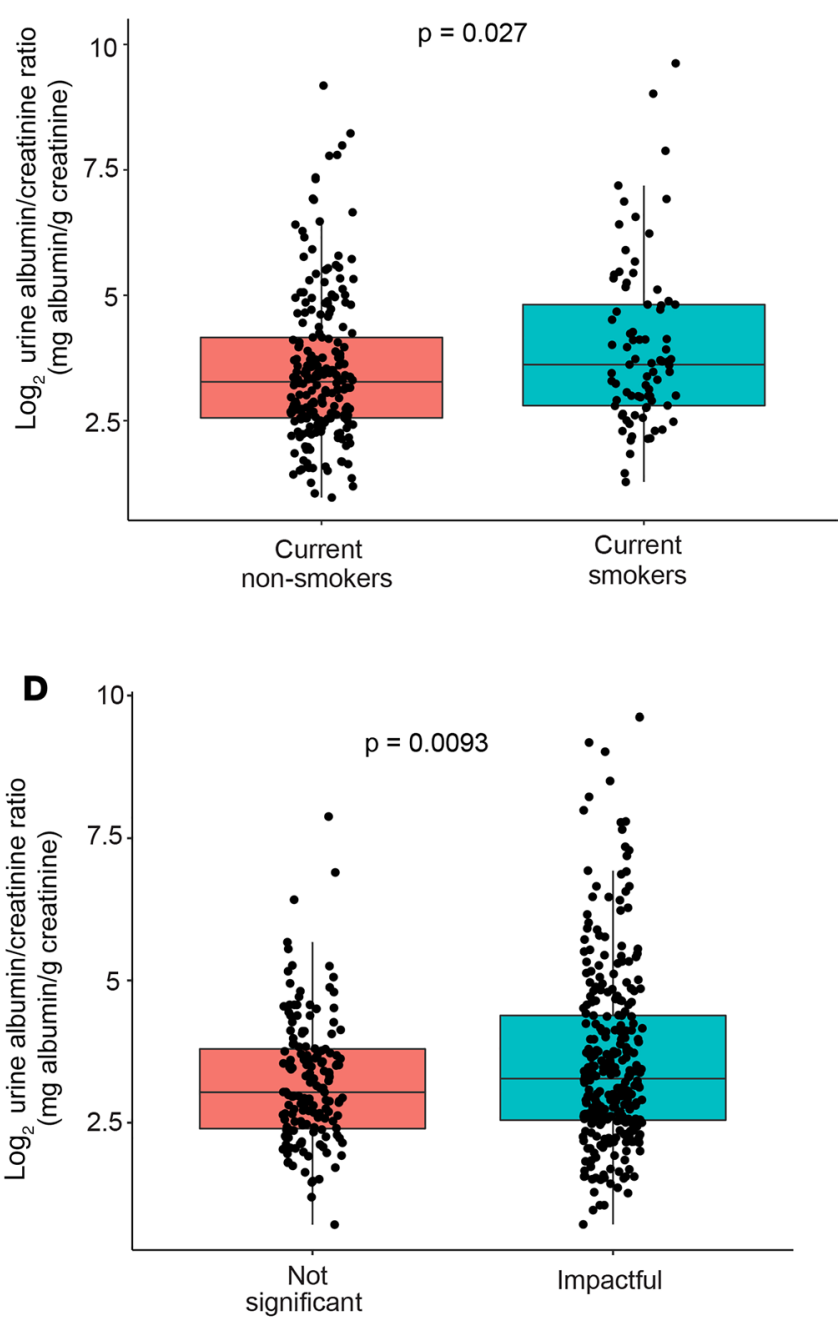

$\operatorname{CAT}(\geq 10)$

Figure 2. Urine albumin/creatinine ratios (UACR) are higher in subjects with COPD and correlate with worse spirometry and respiratory symptom severity by the CAT score. (A) UACR ( $\log _{2} \mathrm{mg} / \mathrm{g}$ ) was measured in SPIROMICS participants and compared between never smokers $(n=64)$, smokers without airflow obstruction $(n=109)$, participants with mild/moderate COPD $(n=139)$, and participants severe COPD $(n=168)$. (B) UACR in participants with COPD who are current nonsmokers $(n=219)$ and current smokers $(n=82)$. (C) UACR and association with postbronchodilator FEV $\%$ predicted in all participants, including never smokers ( $n=63$; red), smokers without airflow obstruction ( $n=109$; green), participants with mild/moderate COPD ( $n=139$; blue), and participants with severe COPD ( $n=168$; purple). (D) UACR compared in participants with mild symptoms (not significant, $n=156)$ and those with more severe respiratory symptoms (impactful, $n=294$ ) using COPD Assessment Test (CAT) scores of $\geq 10$ as a cutoff for impactful symptoms. Data (A, B, D) are presented as median, with box indicating upper and lower quartiles, whiskers indicating extrema, and $P$ values calculated by Tukey's range test (A) or unadjusted linear regression models (B and $\mathbf{D}$ ). Linear associations (C) were implemented with unadjusted linear regression models.

without airflow obstruction $\left(4.13 \times 10^{9}\right.$ copies/g vs. $1.59 \times 10^{9}$ copies $\left./ g, P<0.001\right)$, participants with mild/moderate COPD $\left(3.92 \times 10^{9}\right.$ copies/g vs. $2.38 \times 10^{9}$ copies $\left./ g, P<0.001\right)$, and participants with severe COPD $\left(4.13 \times 10^{9}\right.$ copies/g vs. $2.29 \times 10^{9}$ copies/g, $\left.P<0.001\right)$ in unadjusted and adjusted analyses (Figure 5, A and B, and Table 5). In males only, u-mtDNA was significantly associated with $\mathrm{FEV}_{1} \%$ predicted $(\hat{\beta}=-0.13[-0.24,-0.01], P=0.027)$, although this was no longer significant after adjustment ( $\hat{\beta}=-0.10[-0.22,0.02], P=0.091$, Figure 5C and Table 6). In females, while not associated with $\mathrm{FEV}_{1}$ $\%$ predicted, u-mtDNA was significantly associated with worse $6 \mathrm{MWD}(\hat{\beta}=-0.02[-0.04,-0.004], P=$ $0.016)$ and was higher in females with more significant symptoms by SGRQ $(\hat{\beta}=0.01[0.0005,0.02], P$ $=0.004)$ and CAT $(\beta=0.50[0.11,0.89], P=0.012 ;$ Figure $5, \mathrm{D}-\mathrm{F})$. These associations largely remained significant in models that adjusted for age, BMI, and smoking status and were not observed to be 
Table 2. Urine albumin/creatinine ratio between subgroups

\begin{tabular}{|c|c|c|c|c|}
\hline Subgroups compared & \multicolumn{2}{|c|}{ Unadjusted } & \multicolumn{2}{|c|}{ Adjusted for age, sex, BMI, \& smoking status } \\
\hline $\begin{array}{l}\text { Never smokers - Smokers } \\
\text { without airflow obstruction }\end{array}$ & $\begin{array}{c}-0.02 \\
(-0.46,0.42)\end{array}$ & 0.935 & $\begin{array}{c}-0.34 \\
(-0.81,0.12)\end{array}$ & 0.148 \\
\hline $\begin{array}{c}\text { Smokers without airflow } \\
\text { obstruction - Mild/moderate } \\
\text { COPD }\end{array}$ & $\begin{array}{c}0.47 \\
(0.11,0.82)\end{array}$ & 0.010 & $\begin{array}{c}0.38 \\
(0.01,0.75)\end{array}$ & 0.042 \\
\hline $\begin{array}{l}\text { Mild/moderate COPD - } \\
\text { Severe COPD }\end{array}$ & $\begin{array}{c}0.09 \\
(-0.23,0.41)\end{array}$ & 0.600 & $\begin{array}{c}0.15 \\
(-0.17,0.49)\end{array}$ & 0.356 \\
\hline
\end{tabular}

${ }^{A}$ Pairwise contrasts of strata using Tukey's range test (unadjusted and adjusted). $\hat{\beta}$, estimated change $\log _{2}$ UACR with a 1 unit increase in clinical characteristic.

significant in males (Figure 5, D-F, and Table 6). Conversely, there was a significant association between u-mtDNA and radiographic measures of emphysema among males in models that adjusted for age, BMI, and smoking status $\left(\hat{\beta}=0.02[0.0007,0.03], P=0.041\right.$, for $\mathrm{PRM}^{\mathrm{EMPH}} ; \hat{\beta}=0.02[0.001,0.03], P=0.034$, for percent of LAA less than-950 HU), which was not observed in females (Figure 5, G-I, and Table 6). Notably, UACR was not significantly different between males and females in the SPIROMICS cohort; while UACR was associated with more significant respiratory symptoms by CAT in males $\hat{\beta}=0.41$ [0.01, 0.81], $P=0.047$ ), there were no other sex differences with UACR in relation to other clinical outcomes (Supplemental Figure 5 and Supplemental Tables 4 and 5).

\section{Discussion}

In this study, we found associations between u-mtDNA levels and clinical measures of disease severity, especially respiratory symptom burden, that were not observed in the more traditional urinary marker of kidney injury, the UACR. Strikingly, we not only observed stronger associations for u-mtDNA in "healthy" smokers without airflow obstruction, but also contrasting associations for u-mtDNA in males and females, with u-mtDNA associating more with respiratory symptoms in females and more with spirometric and emphysema severity in males. Our findings provide further evidence for a mechanistic role for mitochondrial dysfunction in COPD and suggest that u-mtDNA may shed insight on early COPD and the often-described but rarely explained connection between sex and COPD.

A

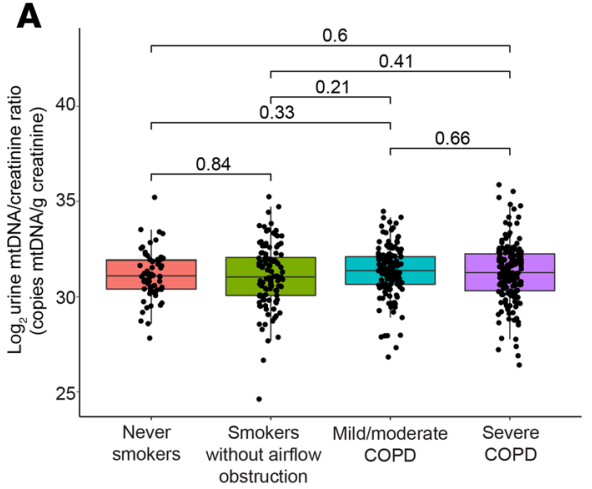

B

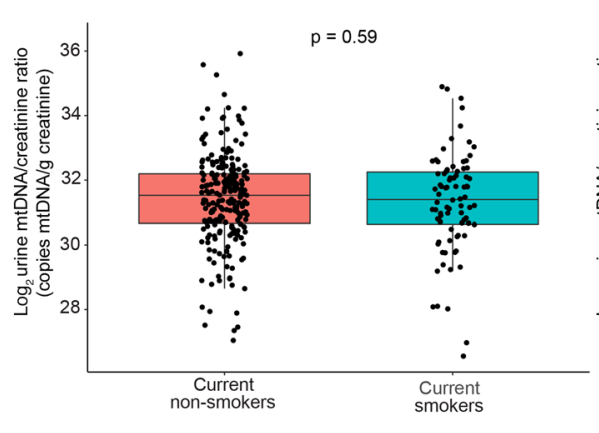

C

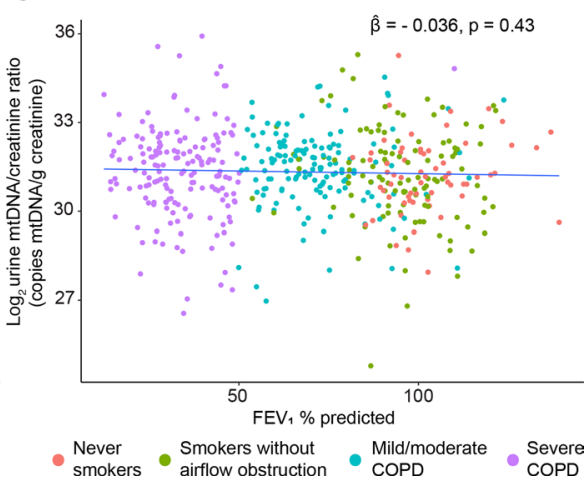

Figure 3. Urine mtDNA (u-mtDNA) levels do not associate with smoking status or spirometric severity in the SPIROMICS cohort. (A) U-mtDNA (log ${ }_{2}$ copies $\mathrm{mtDNA} / \mathrm{g}$ creatinine) was measured in SPIROMICS participants and compared between never smokers $(n=64)$, smokers without airflow obstruction ( $n=109$ ), participants with mild/moderate COPD $(n=139)$, and participants with severe COPD $(n=168)$. (B) U-mtDNA in participants with COPD who are current nonsmokers $(n=219)$ and current smokers $(n=82)$. (C) U-mtDNA and association with postbronchodilator $\mathrm{FEV}_{1} \%$ predicted in all participants, including never smokers ( $n=63$; red), smokers without airflow obstruction ( $n=109$; green), participants with mild/moderate COPD ( $n=142$; blue), and participants with severe COPD ( $n$ $=168$; purple). Data (A and B) are presented as median, with box indicating upper and lower quartiles, whiskers indicating extrema, and $P$ values calculated by Tukey's range test $(\mathbf{A})$ or unadjusted linear regression models $(\mathbf{B})$. Linear associations (C) were implemented with unadjusted linear regression models. 
Table 3. Urine mtDNA between subgroups

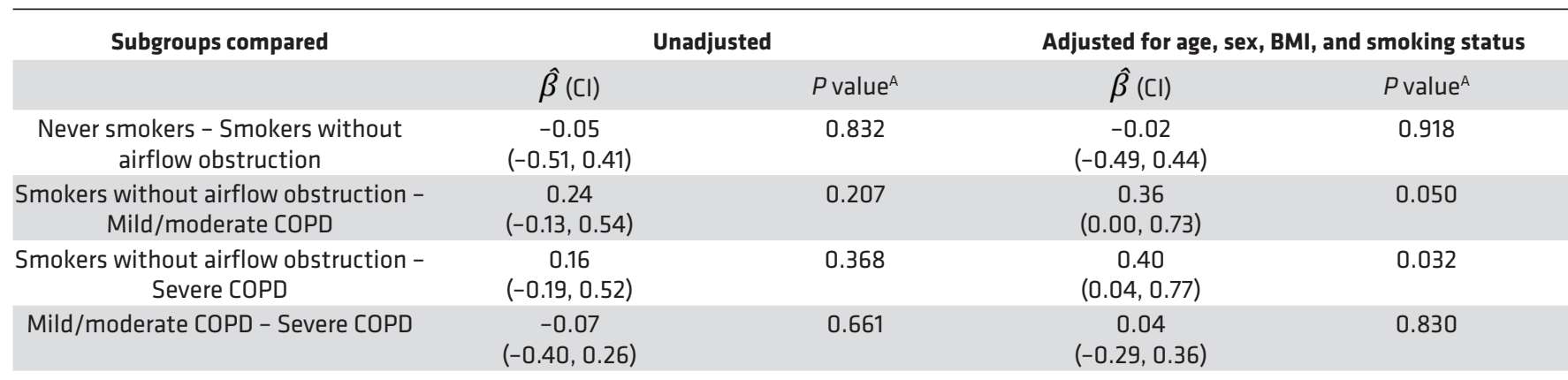

${ }^{A}$ Pairwise contrasts of strata using Tukey's range test (unadjusted and adjusted). $\hat{\beta}$, estimated change $\log _{2}$ urine mtDNA with a 1 unit increase in clinical characteristic.

Given the ample evidence connecting kidney disease with COPD, with albuminuria in many studies associating with future spirometric progression, it is not surprising that there were significant correlations between urinary biomarkers and important clinical outcomes in this study (44, 51-54). Our results with UACR recapitulate these previous studies, although UACR did not associate strongly with other "early" intermediate outcomes or emphysema parameters in the SPIROMICS cohort. By comparison, u-mtDNA expanded upon the associations observed with UACR, with higher u-mtDNA associating with worse 6MWD, SGRQ, and CAT scores in both unadjusted and adjusted analyses. These associations were especially prominent in smokers without airflow obstruction, which may suggest that a pathologic process has already started in these "healthy" subjects and supports previous results that show that increased symptom burden in this population is not benign (64). Although UACR and u-mtDNA were associated with different clinical parameters in this study, they were associated with each other, perhaps suggesting that they are different outputs of a common pathologic process in COPD.

The source of u-mtDNA in our study is unknown; despite u-mtDNA being examined previously in a variety of clinical scenarios, including both acute and chronic kidney injury (26, 32, 33, 36-42), it is not clear if mtDNA detected in urine arises from the kidney intrinsically or whether it is filtered and secreted (or at least not reabsorbed) from circulating extracellular mtDNA. In at least 1 study, exogenous mtDNA given intravascularly to rodents did not increase circulating mtDNA but increased u-mtDNA (26). U-mtDNA may also originate from renal cells, including glomerular or tubular epithelial cells (56), endothelial cells $(44)$, and immune cells $(6,12)$, as well as lung-derived cell sources $(5-11,16)$ or muscle $(65)$; further mechanistic studies are needed to identify the source of extracellular mtDNA in COPD. Whether u-mtDNA in COPD is a marker of disease or is pathogenic in itself remains to be determined. Some studies have shown that giving mice exogenous mtDNA may increase markers of inflammation but does not induce bona fide kidney injury $(26,66)$.

The contrasting associations between u-mtDNA and clinical outcomes in male and female subjects are particularly interesting and thought provoking. It is unclear why u-mtDNA would differ by sex, an effect that is independent of smoking and is observed among never smokers. mtDNA is maternally inherited, and it is possible that our results are supportive of potentially different heritable genetic risk factors for COPD between men and women $(67,68)$. In this study, u-mtDNA correlated with increased respiratory symptom burden in females only, which may be consistent with studies showing that women report greater dyspnea $(60,61)$ and have an increased rate of exacerbation $(63)$ than men. In general, women are more susceptible to smoke exposure; have more severe disease, despite lower cumulative tobacco consumption; and experience earlier onset of COPD, faster decline in $\mathrm{FEV}_{1}$, and more frequent exacerbations (69-73). In addition, females develop a different type of COPD than males, with less severe emphysematous destruction but thicker small airway walls (70). Mitochondria-related heritable factors, as well as metabolite differences, have been differentially observed between males and females $(67,74)$. Our findings herein add to the body of literature that exists that highlights sex differences in not only the clinical presentation, but also the underlying pathobiology of COPD (75-77). Future studies using animal models of COPD may be insightful in elucidating the mechanisms behind these observations (78). 
Table 4. Urine mtDNA and clinical characteristics within subgroups

\begin{tabular}{|c|c|c|c|c|}
\hline & \multicolumn{2}{|c|}{ Unadjusted } & \multicolumn{2}{|c|}{ Adjusted for age, sex, BMI, and smoking status ${ }^{A}$} \\
\hline & $\hat{\beta}(\mathrm{Cl})$ & $P$ value $^{\mathrm{B}}$ & $\hat{\beta}(\mathrm{Cl})$ & $P$ value ${ }^{B}$ \\
\hline \multicolumn{5}{|l|}{ FEV $\%$ predicted } \\
\hline Never smokers & $0.31(-0.19,0.82)$ & 0.230 & $0.37(-0.12,0.85)$ & 0.147 \\
\hline $\begin{array}{l}\text { Smokers without airflow } \\
\text { obstruction }\end{array}$ & $-0.28(-0.72,0.16)$ & 0.214 & $-0.09(-0.50,0.32)$ & 0.679 \\
\hline \multicolumn{5}{|l|}{ 6MWD (meters) } \\
\hline All & $-0.02(-0.03,-0.01)$ & 0.002 & $-0.01(-0.02,-0.001)$ & 0.031 \\
\hline Never smokers & $-0.03(-0.07,-0.001)$ & 0.048 & $-0.02(-0.06,0.02)$ & 0.280 \\
\hline $\begin{array}{l}\text { Smokers without airflow } \\
\text { obstruction }\end{array}$ & $-0.04(-0.07,-0.01)$ & 0.004 & $-0.02(-0.04,0.01)$ & 0.298 \\
\hline Never smokers & $0.01(-0.02,0.03)$ & 0.650 & $0.002(-0.02,0.03)$ & 0.854 \\
\hline $\begin{array}{c}\text { Smokers without airflow } \\
\text { obstruction }\end{array}$ & $0.03(0.01,0.04)$ & 0.002 & $0.01(-0.002,0.03)$ & 0.094 \\
\hline Mild/moderate COPD & $-0.002(-0.01,0.01)$ & 0.767 & $-0.0009(-0.01,0.01)$ & 0.895 \\
\hline Severe COPD & $0.003(-0.01,0.02)$ & 0.688 & $-0.005(-0.02,0.01)$ & 0.634 \\
\hline \multicolumn{5}{|l|}{ CAT $(\geq 10)$} \\
\hline All & $0.36(0.08,0.64)$ & 0.013 & $0.35(0.08,0.62)$ & 0.013 \\
\hline Never smokers & $-0.09(-0.84,0.66)$ & 0.812 & $-0.03(-0.70,0.65)$ & 0.936 \\
\hline $\begin{array}{l}\text { Smokers without airflow } \\
\text { obstruction }\end{array}$ & $1.09(0.48,1.70)$ & $<0.001$ & $0.91(0.32,1.51)$ & 0.003 \\
\hline Mild/moderate COPD & $0.06(-0.43,0.55)$ & 0.804 & $-0.07(-0.58,0.43)$ & 0.780 \\
\hline
\end{tabular}

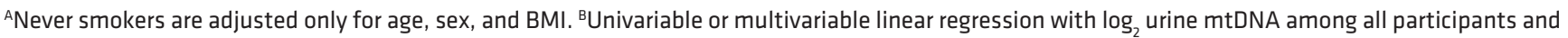
within each group. $\hat{\beta}$, estimated change $\log _{2}$ urine mtDNA with a 1 unit increase in clinical characteristic; FEV ${ }_{1}$, forced expiratory volume in 1 second; $6 \mathrm{MWD}$, 6-minute walk distance; SGRQ, St. George's Respiratory Questionnaire; CAT, COPD Assessment Test.

Our study is the first to our knowledge to examine u-mtDNA in COPD, and it benefited from having a very large, well-characterized, prospective cohort that is rich in clinical information. The SPIROMICS cohort is additionally enriched for participants with early COPD and milder disease, which allows for the exploration of "early" mechanisms in this population. We have extensive experience in studies involving extracellular mtDNA, having examined the utility of this biomarker in other diseases, and we have, over time, refined our protocols to allow for accurate quantitation $(25,79)$. We normalized raw u-mtDNA copy numbers with urine creatinine from the same subjects and further adjusted for BMI, a representation of muscle mass that is known to affect creatinine levels $(80,81)$.

Our study has several limitations. The smoking status was determined by self-report. Levels of urine cotinine, a biomarker of cigarette smoke exposure, have been assessed in the SPIROMICS population but were not analyzed in this study to verify individual smoking status. The surveys given at each study visit screen broadly for genitourinary conditions, including diseases of the bladder and prostate, and therefore do not capture accurately the proportion of patients with true renal disease. We chose to normalize our data to urine creatinine in the spot (untimed) urine samples, in a similar fashion as UACR to assess albuminuria, since 24-hour urine was not collected in the SPIROMICS cohort. The conventional 24-hour urine collection can also be a cumbersome procedure that is subject to errors from improper or incomplete collection. We analyzed UACR and u-mtDNA in models adjusted for age, sex (where appropriate), BMI, and smoking but not study site. This decision stemmed from the fact that, despite opportunistically sampling the available inventory, many sites were heavily underrepresented in 
A
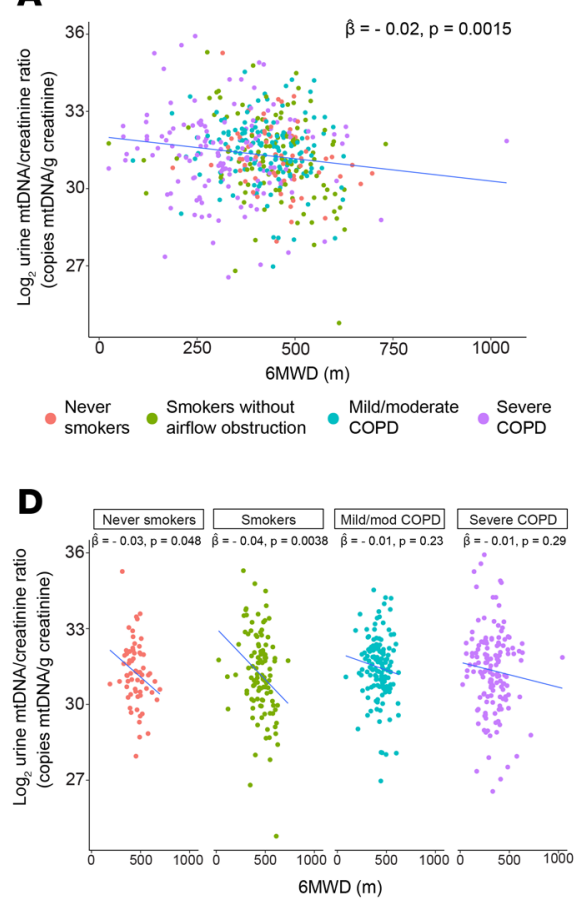

B

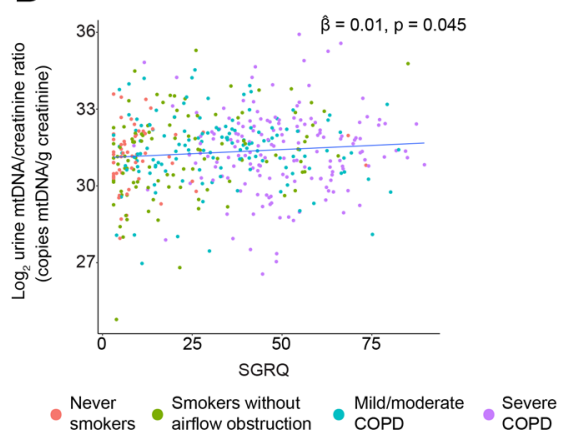

$\mathbf{E}$

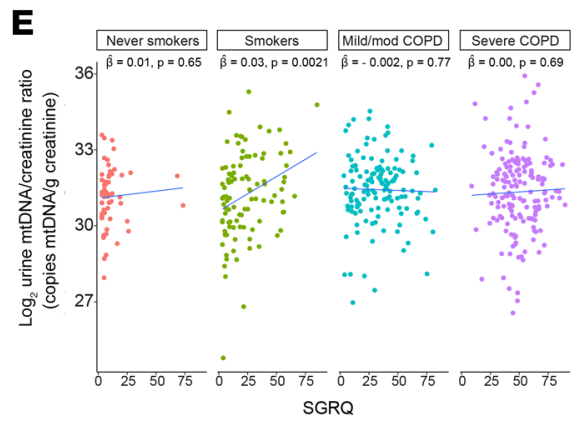

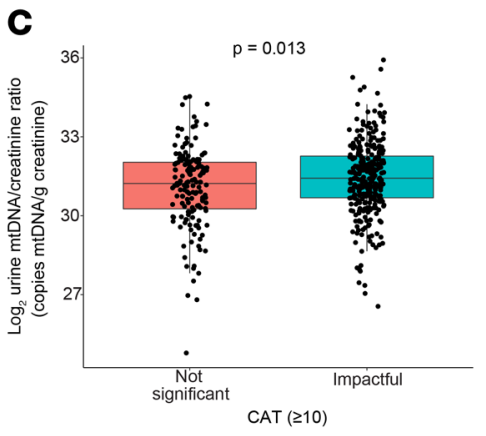

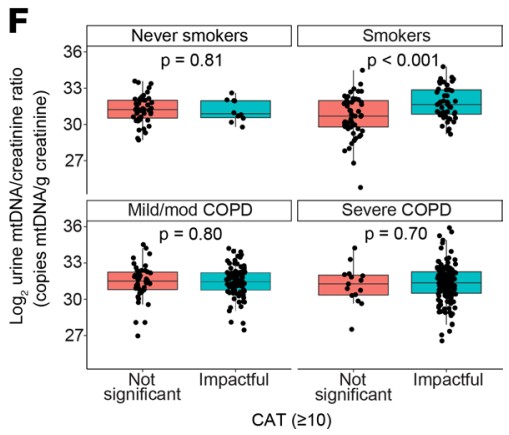

Figure 4. U-mtDNA levels associate with exercise capacity and symptom severity in the SPIROMICS cohort, especially among smokers without COPD. (A-C) Association between u-mtDNA ( $\log _{2}$ copies mtDNA/g creatinine) in all participants (never smokers, $n=61-64$; smokers without airflow obstruction/"smokers", $n=104-109$; participants with mild/moderate COPD, $n=135-137$; participants with severe COPD, $n=149-162$ ) and respiratory symptoms as measured by 6-minute walk distance (6MWD; m, meters) (A), St. George's Respiratory Questionnaire (SGRQ) (B), and COPD Assessment Test (CAT) (not significant, $n=156$; impactful, $n=297$ ) (C). (D-F) Association between u-mtDNA and respiratory symptoms as measured by 6MWD (D), SCRQ (E), and CAT (F) within never smokers $(n=56-64)$, smokers without airflow obstruction/"smokers" ( $n=101-109)$, participants with mild/moderate COPD ( $n=134-137)$, and participants with severe COPD ( $n=149-162)$. Linear associations (A, B, D, E) were implemented with unadjusted linear regression models. Data $(\mathbf{C}$ and $\mathbf{F}$ ) are presented as median, with box indicating upper and lower quartiles, whiskers indicating extrema, and $P$ values calculated by unadjusted linear regression models.

our measured samples, an imbalance that would likely reduce our statistical power significantly with adjustment. Instead of removing these data points or grouping them together, we decided to analyze the entire data set without adjusting for clinical site. Aside from BMI and urine creatinine, we have no other biological rationale to make us believe that study subject location would affect u-mtDNA, although we recognize the potential for unmeasured factors that may be unaccounted for in our analyses. We performed many statistical tests in this study and recognize the potential for type I errors, given our level of significance; while these analyses are largely exploratory, the clustering of significant associations in related clinical parameters (such as 6MWD, SGRQ, and CAT) suggests to us that there is a true biological phenomenon underlying our findings.

In conclusion, extracellular u-mtDNA associates with an increased respiratory burden phenotype in COPD, especially in smokers and women. Further research is needed to uncover the source and meaning of $\mathrm{u}-\mathrm{mtDNA}$, as well as the role of mitochondrial dysfunction in the biological processes underlying COPD pathogenesis and progression, especially with regard to sex differences in disease presentation.

\section{Methods}

Study design and sample collection. SPIROMICS (ClinicalTrials.gov NCT01969344) is an ongoing longitudinal, prospective, multicenter observational study (82) that recruited never smokers ( $\leq 1$ pack-year of tobacco-smoking history) and ever smokers (current or former smokers with $\geq 20$ pack-years, also referred to as smokers) without or with airflow obstruction (64). Clean-catch urine was collected and stored at $-80^{\circ} \mathrm{C}$ before thawing and processing. For this study, urine samples were opportunistically sampled from available inventory. Clinical data were collected at the baseline and follow-up study visits, including demographics, comorbidities, questionnaires, cigarette smoke exposure, and 6MWD (82). 
A

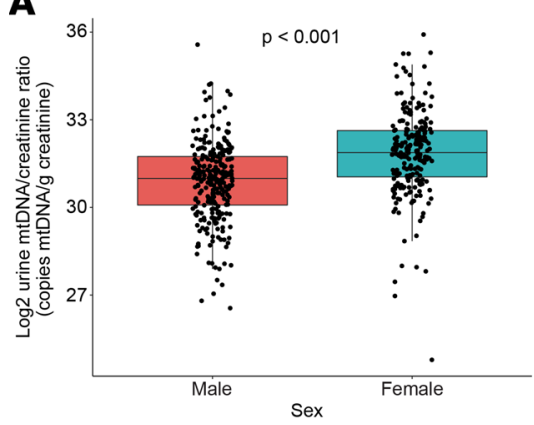

D

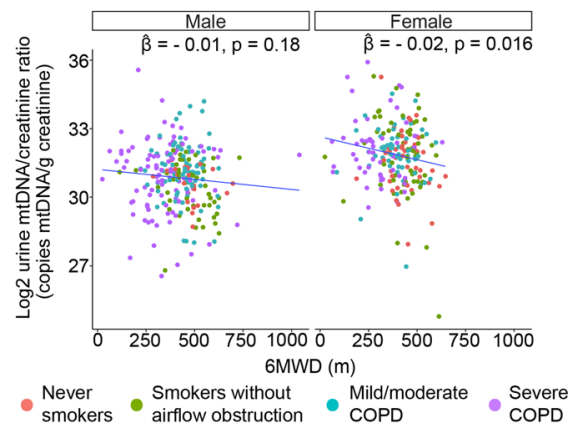

G

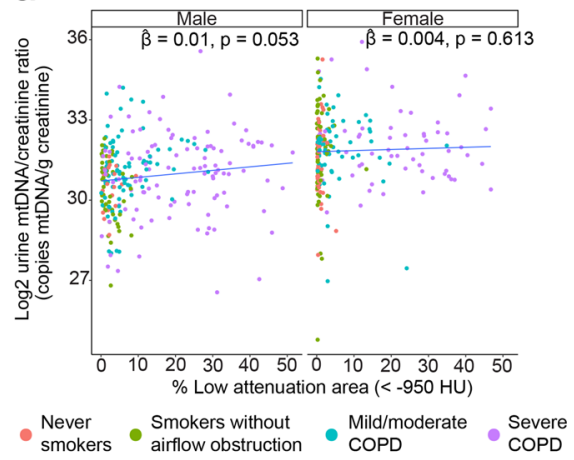

B

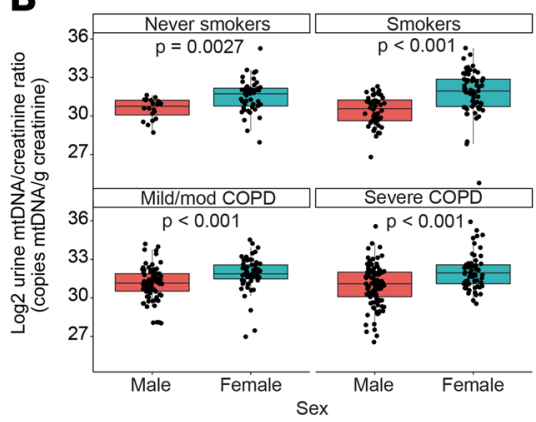

E

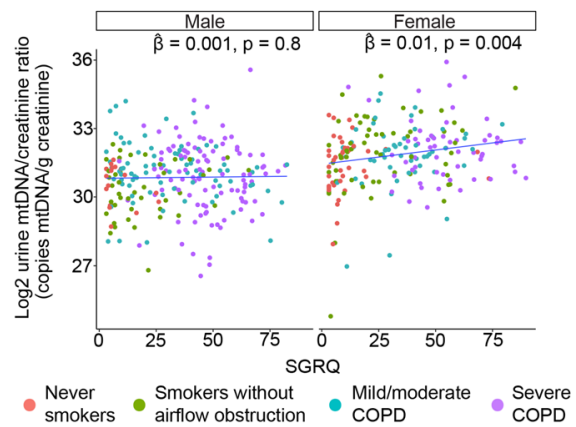

H

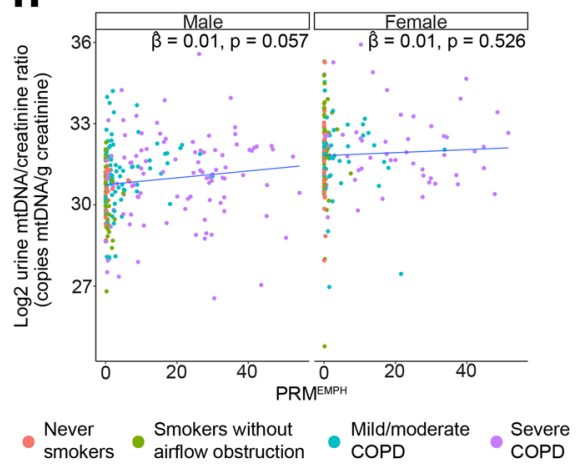

C

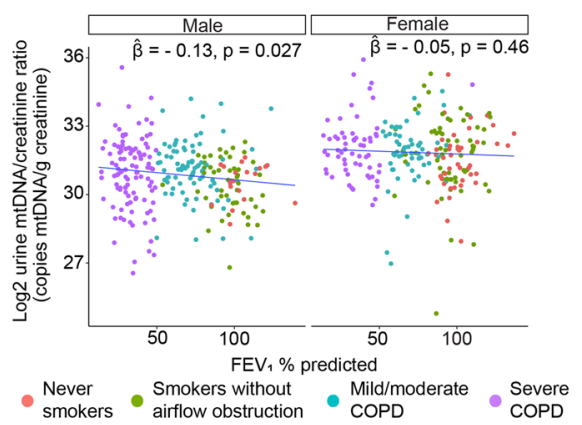

$\mathbf{F}$

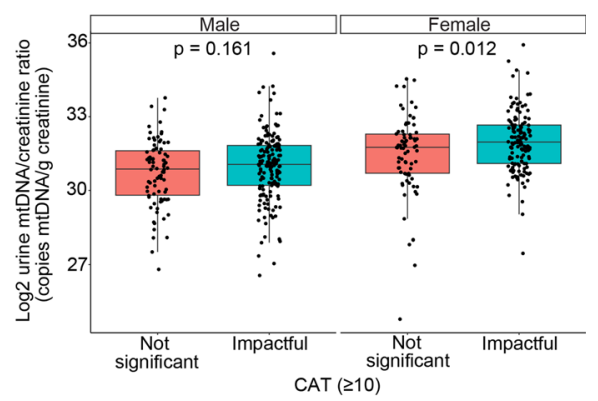

I

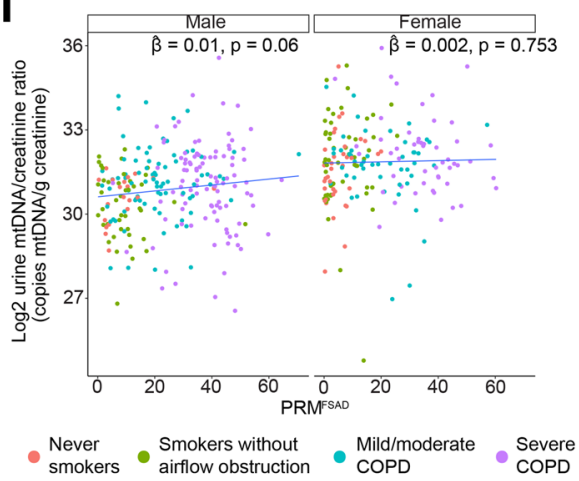

Figure 5. U-mtDNA levels are higher in women, and higher u-mtDNA levels associate with worse exercise capacity and more severe respiratory symptoms in women but not men. (A and B) U-mtDNA ( $\log _{2}$ copies mtDNA/g creatinine) levels in males $(n=258)$ compared with females $(n=225)$ in all participants (A) and within each subgroup (never smokers male, $n=20$, and female, $n=44$; smokers without airflow obstruction/"smokers" male, $n=48$, and female $n=61$; mild $/$ moderate COPD male, $n=83$, and female, $n=59$; severe COPD male, $n=107$, and female $n=61)(B)$. (C-I) U-mtDNA and association with postbronchodilator FEV $\%$ predicted (C), 6MWD (D), SGRQ (E), CAT (not significant male, $n=82$, and female, $n=74$; impactful male, $n=162$, and female, $n=135)(\mathbf{F})$, percentage of LAA less than $-950 \mathrm{HU}(\mathbf{G})$, emphysema by parametric response mapping (PRM ${ }^{\mathrm{EMPH}}$ ) $(\mathbf{H})$, and functional small airway disease by parametric response mapping (PRM $\left.{ }^{F S A D}\right)(\mathbf{I})$ within males and females (never smokers male, $n=18-20$, and female, $n=36-44$; smokers without airflow obstruction male, $n=43-48$, and female, $n=53-61$; mild $/ \mathrm{moderate}$ COPD male, $n=76-83$, and female, $n=50$-59; severe COPD male, $n=94-107$, and female, $n=51-61)$. Data (A, B, F) are presented as median, with box indicating upper and lower quartiles, whiskers indicating extrema, and $P$ values calculated by unadjusted linear regression models. Linear associations (C-E and $\mathbf{G}-\mathbf{I})$ were implemented with unadjusted linear regression models.

Symptom burden was quantified with the CAT and health-related quality of life (HRQL) with the SGRQ total score. The extent of emphysema and airway-wall abnormality was characterized with HRCT scans of the lung, using Imbio (PRM) and VIDA Diagnostics software; percent emphysema was defined as LAA less than $-950 \mathrm{HU}$ at total lung capacity (83).

Urine processing and quantification of UACR. Samples were thawed on ice and vortexed briefly to mix. A total of $50 \mu \mathrm{L}$ of urine was diluted with $170 \mu \mathrm{L}$ of PBS and then centrifuged at $700 \mathrm{~g}$ at $4^{\circ} \mathrm{C}$ for 5 minutes to remove cells and cellular debris. DNA was isolated using $180 \mu \mathrm{L}$ of the supernatant with the QIAamp DSP DNA Blood Mini Kit (61104; Qiagen), according to the manufacturer's microcentrifuge protocol. A total of $200 \mu \mathrm{L}$ of the provided elution buffer was used to collect the DNA. 
Table 5. Urine mtDNA in females compared with males

\begin{tabular}{|c|c|c|c|c|}
\hline & \multicolumn{2}{|c|}{ Unadjusted } & \multicolumn{2}{|c|}{ Adjusted for age, BMI, \& smoking status } \\
\hline All & $\begin{array}{c}0.97 \\
(0.72,1.22)\end{array}$ & $<0.001$ & $\begin{array}{c}1.01 \\
(0.75,1.26)\end{array}$ & $<0.001$ \\
\hline Never smokers & $\begin{array}{c}0.99 \\
(0.37,1.61)\end{array}$ & 0.003 & $\begin{array}{c}1.12 \\
(0.49,1.75)\end{array}$ & $<0.001$ \\
\hline $\begin{array}{c}\text { Smokers without airflow } \\
\text { obstruction }\end{array}$ & $\begin{array}{c}1.40 \\
(0.83,1.97)\end{array}$ & $<0.001$ & $\begin{array}{c}1.43 \\
(0.86,2.01)\end{array}$ & $<0.001$ \\
\hline Severe COPD & $\begin{array}{c}1.11 \\
(0.64,1.58)\end{array}$ & $<0.001$ & $\begin{array}{c}1.18 \\
(0.69,1.67)\end{array}$ & $<0.001$ \\
\hline
\end{tabular}

${ }^{A}$ Never smokers are adjusted only for age and BMI. ${ }^{B}$ Univariable or multivariable linear regression with $\log _{2}$ mtDNA as dependent variable. $\hat{\beta}$, estimated difference in $\log _{2}$ urine mtDNA in females compared with males.

Before quantification, the DNA solution was diluted 1:5 with nuclease-free deionized, distilled $\mathrm{H}_{2} \mathrm{O}$. mtDNA levels were measured by SYBR Green dye-based quantitative PCR (qPCR) assay using a PRISM 7500 sequence detection system (Applied Biosystems) as previously described (25). Briefly, the following primer sequences were used: human NADH dehydrogenase 1 gene (forward 5'-ATACCCATGGCCAACCTC-3', reverse 5'-GGGCCTTTGCGTAGTTGTAT-3'). For absolute quantitation of mtDNA, a standard curve was generated from DNA plasmid constructs in serial dilutions (ORIGENE, SC101172; GenScript, NM_173708). Sample (5 $\mu$ L) was added to each well in triplicate, along with a no-template control. The thermal profile was carried out as follows: 2 minutes at $50^{\circ} \mathrm{C}, 10$ minutes at $95^{\circ} \mathrm{C}, 40$ cycles for 15 seconds at $95^{\circ} \mathrm{C}$, and 1 minute at $60^{\circ} \mathrm{C}$. UACR was determined by immunoassay with Siemens DCA Microalbumin/Creatinine Reagent Kit (catalog 6011A) using a separate sample aliquot, according to the manufacturer's instructions. The concentration of mtDNA in urine was calculated in copies per $\mu \mathrm{L}$, as previously described (25), followed by normalization to urine creatinine; final values were reported in copies of mtDNA per $\mathrm{g}$ of creatinine.

Statistics. Clinical characteristics of SPIROMICS participants for whom urine creatinine and $\mathrm{u}$-mtDNA were measured were compared with those of all SPIROMICS participants summarized using medians and interquartile intervals, or counts and percentages as appropriate. Both u-mtDNA and UACR were analyzed on the $\log _{2}$ scale to account for right-skewed distributions. Post hoc pairwise differences between subgroups were evaluated using Tukey's range test on the transformed data and are presented in the figures and tables. For comparison, untransformed medians were provided in the text, and the nonparametric Kruskal-Wallis test was implemented and presented, as well. Associations between u-mtDNA, UACR, and baseline characteristics were performed using unadjusted linear models. Associations with postbronchodilator $\mathrm{FEV}_{1} \%$ predicted, $6 \mathrm{MWD}$, SGRQ, CAT, and CT measures of lung structure were further evaluated with linear models adjusted for age, sex, BMI, and current smoking status at baseline, overall, and within COPD subgroups. Given the previous literature showing differences in mtDNA between males and females, an a priori subgroup analysis for sex was performed. The effect size from the linear models is reported as a $\beta$ coefficient with a corresponding $95 \% \mathrm{CI}$, representing the change in the outcome variable for a unit change in the explanatory value, holding all other variables in the model constant. Analysis was conducted in R (84), and figures were produced using the package ggplot2 (85). All statistical tests were 2 sided and were performed using a significance level of $P<0.05$.

Study approval. The study protocols for SPIROMICS were approved by the IRBs at all participating sites: Columbia University Medical Center, Johns Hopkins University, National Jewish Health, Temple University, University of Alabama at Birmingham, UCLA, UCSF, University of Illinois at Chicago, University of Iowa, University of Michigan, University of North Carolina Chapel Hill, University of Utah, and Wake Forest University. All participants provided written informed consent before inclusion in the respective study. 
Table 6. Urine mtDNA and clinical characteristics within males and females

\begin{tabular}{|c|c|c|c|c|}
\hline & \multicolumn{2}{|c|}{ Unadjusted } & \multicolumn{2}{|c|}{ Adjusted for age, BMI, and smoking status } \\
\hline \multicolumn{5}{|c|}{ FEV $\%$ predicted } \\
\hline Females & $-0.05(-0.18,0.08)$ & 0.463 & $-0.05(-0.19,0.08)$ & 0.441 \\
\hline \multicolumn{5}{|c|}{ 6MWD (meters) } \\
\hline Males & $-0.01(-0.02,0.004)$ & 0.181 & $-0.01(-0.02,0.01)$ & 0.249 \\
\hline \multicolumn{5}{|l|}{ SGRQ } \\
\hline Males & $0.001(-0.01,0.01)$ & 0.799 & $0.0004(-0.01,0.01)$ & 0.776 \\
\hline Females & $0.01(0.004,0.02)$ & 0.004 & $0.01(0.0005,0.02)$ & 0.009 \\
\hline \multicolumn{5}{|l|}{ CAT $(\geq 10)$} \\
\hline Males & $0.26(-0.10,0.62)$ & 0.161 & $0.25(-0.12,0.62)$ & 0.186 \\
\hline Females & $0.50(0.11,0.89)$ & 0.012 & $0.49(0.08,0.89)$ & 0.020 \\
\hline \multicolumn{5}{|l|}{ PRMEMPH } \\
\hline Males & $0.01(-0.0003,0.03)$ & 0.057 & $0.02(0.0007,0.03)$ & 0.041 \\
\hline Females & $0.01(-0.01,0.02)$ & 0.526 & $0.01(-0.01,0.03)$ & 0.319 \\
\hline \multicolumn{5}{|l|}{ PRMFSAD } \\
\hline Males & $0.01(-0.0004,0.02)$ & 0.060 & $0.01(-0.003,0.02)$ & 0.167 \\
\hline Females & $0.002(-0.01,0.02)$ & 0.753 & $0.003(-0.01,0.02)$ & 0.696 \\
\hline
\end{tabular}

AUnivariable or multivariable linear regression with $\log _{2}$ urine mtDNA as among all participants and within each group. $\hat{\beta}$, estimated change log ${ }_{2}$ urine mtDNA with a 1 unit increase in clinical characteristic; FEV ${ }_{1}$, forced expiratory volume in 1 second; 6MWD, 6-minute walk distance; SCRQ, St. Ceorge's Respiratory Questionnaire; CAT, COPD Assessment Test; LAA, low attenuation area; HU, Hounsfield units; PRM ${ }^{\mathrm{EMPH}}$, emphysema by parametric response mapping, $P R M^{F S A D}$, functional small airway disease by parametric response mapping.

\section{Author contributions}

AMKC, KN, and MEC contributed to the conception and design of the study. IZB, JMW, ATH, WWL, CBC, APC, GJC, JAK, RP, NNH, RPB, RGB, SPP, PGW, JLC, MKH, FJM, and the SPIROMICS Investigators contributed to the acquisition of the samples and data. MCR performed the measurements. KLH, $\mathrm{CO}$, and KVB performed the statistical analyses. WZZ, MCR, KLH, and SMC drafted the initial manuscript. WZZ, MCR, KLH, CO, WWL, RP, MKH, KVB, FJM, AMKC, KN, SMC, and MEC contributed to revisions of the manuscript for critically important intellectual content. All of the authors approved this version of the manuscript to be published.

\section{Acknowledgments}

This work was supported by NIH grants P01 HL114501 (AMKC), R01 HL132198 and R01 HL133801 (AMKC and MEC), R00 HL125899 (SMC), KL2-TR-002385 (KN), U01 HL128964, U01 HL137880, P01 HL114501, R01 HL122438, R01 HL136682 (FJM), and T32-HL134629 and a research grant from the Stony Wold-Herbert Fund (WZZ). The authors thank Kristen Schiffer and the Weill Cornell Medicine Clinical \& Translational Science Center (CTSC), supported by the National Center For Advancing Translational Sciences of the NIH (UL1TR000457) for technical support. The authors thank the SPIROMICS participants and participating physicians, investigators, and staff for making this research possible. More information about the study and how to access SPIROMICS data is at www.spiromics.org. We would like to acknowledge the following current and former investigators of the SPIROMICS sites and reading centers: Neil E. Alexis, Wayne H. Anderson, Mehrdad Arjomandi, Igor Barjaktarevic, R. Graham Barr, Lori A. Bateman, Surya P. Bhatt, Eugene R. Bleecker, Richard C. Boucher, Russell P. Bowler, Stephanie A. Christenson, Alejandro P. Comellas, Christopher B. Cooper, David J. Couper, Gerard J. Criner, Ronald G. Crystal, Jeffrey L. Curtis, Claire M. Doerschuk, Mark T. Dransfield, Brad Drummond, Christine M. Freeman, Craig Galban, MeiLan K. Han, Nadia N. Hansel, Annette T. Hastie, Eric A. Hoffman, Yvonne 
Huang, Robert J. Kaner, Richard E. Kanner, Eric C. Kleerup, Jerry A. Krishnan, Lisa M. LaVange, Stephen C. Lazarus, Fernando J. Martinez, Deborah A. Meyers, Wendy C. Moore, John D. Newell Jr., Robert Paine III, Laura Paulin, Stephen P. Peters, Cheryl Pirozzi, Nirupama Putcha, Elizabeth C. Oelsner, Wanda K. O’Neal, Victor E. Ortega, Sanjeev Raman, Stephen I. Rennard, Donald P. Tashkin, J. Michael Wells, Robert A. Wise, and Prescott G. Woodruff. The project officers from the Lung Division of the National Heart, Lung, and Blood Institute were Lisa Postow and Lisa Viviano; SPIROMICS was supported by contracts from the NIH/NHLBI (HHSN268200900013C, HHSN268200900014C, HHSN268200900015C, HHSN268200900016C, HHSN268200900017C, HHSN268200900018C, HHSN268200900019C, HHSN268200900020C) and grants from the NIH/NHLBI (U01 HL137880 and U24 HL141762), and was supplemented by contributions made through the Foundation for the NIH and the COPD Foundation from AstraZeneca/MedImmune, Bayer, Bellerophon Therapeutics, Boehringer-Ingelheim Pharmaceuticals Inc., Chiesi Farmaceutici S.p.A., Forest Research Institute Inc., GlaxoSmithKline, Grifols Therapeutics Inc., Ikaria Inc., Novartis Pharmaceuticals Corporation, Nycomed GmbH, ProterixBio, Regeneron Pharmaceuticals Inc., Sanofi, Sunovion, Takeda Pharmaceutical Company, and Theravance Biopharma and Mylan.

Address correspondence to: Mary E. Choi, Division of Nephrology and Hypertension, Joan and Sanford I. Weill Department of Medicine, Weill Cornell Medicine, 525 East 68th Street, Box 3, New York, New York 10065, USA. Email: mec2025@med.cornell.edu.

1. Martinez FJ, et al. At the Root: Defining and Halting Progression of Early Chronic Obstructive Pulmonary Disease. Am J Respir Crit Care Med. 2018;197(12):1540-1551.

2. Woodruff PG, Agusti A, Roche N, Singh D, Martinez FJ. Current concepts in targeting chronic obstructive pulmonary disease pharmacotherapy: making progress towards personalised management. Lancet. 2015;385(9979):1789-1798.

3. Stockley RA, Halpin DMG, Celli BR, Singh D. Chronic Obstructive Pulmonary Disease Biomarkers and Their Interpretation. Am J Respir Crit Care Med. 2019;199(10):1195-1204

4. Agustí A, Celli B, Faner R. What does endotyping mean for treatment in chronic obstructive pulmonary disease? Lancet. 2017;390(10098):980-987.

5. Białas AJ, et al. Morphometric analysis of mitochondria in lymphocytes of patients with exacerbations of chronic obstructive pulmonary disease - pilot study. Int J Chron Obstruct Pulmon Dis. 2018;13:2313-2318.

6. Bewley MA, et al. Impaired Mitochondrial Microbicidal Responses in Chronic Obstructive Pulmonary Disease Macrophages. Am J Respir Crit Care Med. 2017;196(7):845-855.

7. Brahme A, et al. Metabolic paralysis in systemic immune cells of Chronic Obstructive Pulmonary Disease (COPD) subjects Eur Respir J. 2018;52(suppl_62):PA934.

8. Liu SF, et al. Leukocyte Mitochondrial DNA Copy Number Is Associated with Chronic Obstructive Pulmonary Disease. PLoS One. 2015;10(9):e0138716.

9. Even B, et al. Heme oxygenase-1 induction attenuates senescence in chronic obstructive pulmonary disease lung fibroblasts by protecting against mitochondria dysfunction. Aging Cell. 2018;17(6):e12837.

10. Wiegman $\mathrm{CH}$, et al. Oxidative stress-induced mitochondrial dysfunction drives inflammation and airway smooth muscle remodeling in patients with chronic obstructive pulmonary disease. J Allergy Clin Immunol. 2015;136(3):769-780.

11. Hoffmann RF, et al. Prolonged cigarette smoke exposure alters mitochondrial structure and function in airway epithelial cells. Respir Res. 2013;14:97.

12. Belchamber KBR, et al. Defective bacterial phagocytosis is associated with dysfunctional mitochondria in COPD macrophages. Eur Respir J. 2019;54(4):1802244.

13. Ning W, et al. Comprehensive analysis of gene expression on GOLD-2 Versus GOLD-0 smokers reveals novel genes important in the pathogenesis of COPD. Proc Am Thorac Soc. 2006;3(6):466.

14. Mizumura K, et al. Mitophagy-dependent necroptosis contributes to the pathogenesis of COPD. J Clin Invest. 2014;124(9):3987-4003.

15. Zhang J, Wang J, Wang X, Liu Z, Ren J, Sun T. Early surgery increases mitochondrial DNA release and lung injury in a model of elderly hip fracture and chronic obstructive pulmonary disease. Exp Ther Med. 2017;14(5):4541-4546.

16. Carpagnano GE, et al. Study of mitochondrial DNA alteration in the exhaled breath condensate of patients affected by obstructive lung diseases. J Breath Res. 2016;10(2):026005.

17. Heijink IH, et al. Cigarette smoke-induced damage-associated molecular pattern release from necrotic neutrophils triggers proin flammatory mediator release. Am J Respir Cell Mol Biol. 2015;52(5):554-562.

18. Pouwels SD, et al. Susceptibility for cigarette smoke-induced DAMP release and DAMP-induced inflammation in COPD. Am J Physiol Lung Cell Mol Physiol. 2016;311(5):L881-L892.

19. Pouwels SD, et al. Cigarette smoke-induced necroptosis and DAMP release trigger neutrophilic airway inflammation in mice. Am J Physiol Lung Cell Mol Physiol. 2016;310(4):L377-L386.

20. García N, Chávez E. Mitochondrial DNA fragments released through the permeability transition pore correspond to specific gene size. Life Sci. 2007;81(14):1160-1166.

21. Nakahira K, et al. Autophagy proteins regulate innate immune responses by inhibiting the release of mitochondrial DNA mediated by the NALP3 inflammasome. Nat Immunol. 2011;12(3):222-230.

22. Zhang Q, Itagaki K, Hauser CJ. Mitochondrial DNA is released by shock and activates neutrophils via p38 map kinase. Shock. 2010;34(1):55-59. 
23. Zhou R, Yazdi AS, Menu P, Tschopp J. A role for mitochondria in NLRP3 inflammasome activation. Nature. 2011;469(7329):221-225.

24. West AP, et al. Mitochondrial DNA stress primes the antiviral innate immune response. Nature. 2015;520(7548):553-557.

25. Nakahira K, et al. Circulating mitochondrial DNA in patients in the ICU as a marker of mortality: derivation and validation. PLoS Med. 2013;10(12):e1001577; discussion e1001577.

26. Cao H, Wu J, Luo J, Chen X, Yang J, Fang L. Urinary mitochondrial DNA: A potential early biomarker of diabetic nephropathy. Diabetes Metab Res Rev. 2019;35(4):e3131.

27. Simmons JD, et al. Mitochondrial DNA damage associated molecular patterns in ventilator-associated pneumonia: Prevention and reversal by intratracheal DNase I. J Trauma Acute Care Surg. 2017;82(1):120-125.

28. Sun S, et al. Mitochondrial DAMPs increase endothelial permeability through neutrophil dependent and independent pathways PLoS One. 2013;8(3):e59989.

29. Zhang JZ, Liu Z, Liu J, Ren JX, Sun TS. Mitochondrial DNA induces inflammation and increases TLR9/NF-kB expression in lung tissue. Int J Mol Med. 2014;33(4):817-824.

30. Carpagnano GE, et al. Analysis of mitochondrial DNA alteration in new phenotype ACOS. BMC Pulm Med. $2016 ; 16: 31$.

31. Echem C, et al. Mitochondrial DNA: A new driver for sex differences in spontaneous hypertension. Pharmacol Res. 2019;144:142-150.

32. Eirin A, et al. Urinary Mitochondrial DNA Copy Number Identifies Chronic Renal Injury in Hypertensive Patients. Hypertension. 2016;68(2):401-410.

33. Eirin A, et al. Glomerular Hyperfiltration in Obese African American Hypertensive Patients Is Associated With Elevated Urinary Mitochondrial-DNA Copy Number. Am J Hypertens. 2017;30(11):1112-1119.

34. Fazzini F, et al. Mitochondrial DNA copy number is associated with mortality and infections in a large cohort of patients with chronic kidney disease. Kidney Int. 2019;96(2):480-488.

35. Harrington JS, Choi AMK, Nakahira K. Mitochondrial DNA in Sepsis. Curr Opin Crit Care. 2017;23(4):284-290.

36. Hu Q, et al. Urinary Mitochondrial DNA Identifies Renal Dysfunction and Mitochondrial Damage in Sepsis-Induced Acute Kidney Injury. Oxid Med Cell Longev. 2018;2018:8074936.

37. Hu Q, et al. Urinary Mitochondrial DNA Levels Identify Acute Kidney Injury in Surgical Critical Illness Patients. Shock. 2017;48(1):11-17.

38. Jansen MPB, et al. Mitochondrial DNA is Released in Urine of SIRS Patients With Acute Kidney Injury and Correlates With Severity of Renal Dysfunction. Shock. 2018;49(3):301-310.

39. Wei PZ, et al. Urinary mitochondrial DNA level in non-diabetic chronic kidney diseases. Clin Chim Acta. 2018;484:36-39.

40. Wei PZ, et al. Urinary mitochondrial DNA level is an indicator of intra-renal mitochondrial depletion and renal scarring in diabetic nephropathy. Nephrol Dial Transplant. 2018;33(5):784-788.

41. Wei Z, et al. Urinary mitochondrial DNA level as a biomarker of tissue injury in non-diabetic chronic kidney diseases. $B M C$ Nephrol. 2018;19(1):367.

42. Whitaker RM, et al. Urinary mitochondrial DNA is a biomarker of mitochondrial disruption and renal dysfunction in acute kidney injury. Kidney Int. 2015;88(6):1336-1344.

43. Miliotis S, Nicolalde B, Ortega M, Yepez J, Caicedo A. Forms of extracellular mitochondria and their impact in health. Mitochondrion. 2019;48:16-30.

44. Polverino F, et al. A Pilot Study Linking Endothelial Injury in Lungs and Kidneys in Chronic Obstructive Pulmonary Disease. Am J Respir Crit Care Med. 2017;195(11):1464-1476.

45. Incalzi RA, et al. Chronic renal failure: a neglected comorbidity of COPD. Chest. 2010;137(4):831-837.

46. van Gestel YR, et al. Association between chronic obstructive pulmonary disease and chronic kidney disease in vascular surgery patients. Nephrol Dial Transplant. 2009;24(9):2763-2767.

47. Incalzi RA, et al. Chronic renal failure: a neglected comorbidity of COPD. Chest. 2010;137(4):831-837.

48. Bchir S, et al. Concomitant elevations of MMP-9, NGAL, proMMP-9/NGAL and neutrophil elastase in serum of smokers with chronic obstructive pulmonary disease. J Cell Mol Med. 2017;21(7):1280-1291.

49. Wang XR, et al. Increased serum levels of lipocalin-1 and -2 in patients with stable chronic obstructive pulmonary disease. Int $J$ Chron Obstruct Pulmon Dis. 2014;9:543-549.

50. Eagan TM, et al. Neutrophil gelatinase-associated lipocalin: a biomarker in COPD. Chest. 2010;138(4):888-895.

51. Casanova C, et al. Microalbuminuria and hypoxemia in patients with chronic obstructive pulmonary disease. Am J Respir Crit Care Med. 2010;182(8):1004-1010.

52. Bulcun E, Ekici M, Ekici A, Kisa U. Microalbuminuria in chronic obstructive pulmonary disease. COPD. 2013;10(2):186-192.

53. Romundstad S, Naustdal T, Romundstad PR, Sorger H, Langhammer A. COPD and microalbuminuria: a 12-year follow-up study. Eur Respir J. 2014;43(4):1042-1050.

54. Oelsner EC, et al. Albuminuria, Lung Function Decline, and Risk of Incident Chronic Obstructive Pulmonary Disease. The NHLBI Pooled Cohorts Study. Am J Respir Crit Care Med. 2019;199(3):321-332.

55. Trudzinski FC, et al. Consequences of chronic kidney disease in chronic obstructive pulmonary disease. Respir Res. 2019;20(1):151.

56. Pabón MA, et al. Beclin-1 regulates cigarette smoke-induced kidney injury in a murine model of chronic obstructive pulmonary disease. JCI Insight. 2018;3(18):99592.

57. Shayo FK, Lutale J. Albuminuria in patients with chronic obstructive pulmonary disease: a cross-sectional study in an African patient cohort. BMC Pulm Med. 2018;18(1):125.

58. Bozkus F, Dikmen N, Samur A. Microalbuminuria in Subjects With COPD: Relationship to the New Version of Global Initiative for Chronic Obstructive Lung Disease Staging. Respir Care. 2017;62(3):307-314.

59. Ford ES. Urinary albumin-creatinine ratio, estimated glomerular filtration rate, and all-cause mortality among US adults with obstructive lung function. Chest. 2015;147(1):56-67.

60. Han MK, et al. Gender and chronic obstructive pulmonary disease: why it matters. Am J Respir Crit Care Med. 2007;176(12):1179-1184. 
61. de Torres JP, Casanova C, Montejo de Garcini A, Aguirre-Jaime A, Celli BR. Gender and respiratory factors associated with dyspnea in chronic obstructive pulmonary disease. Respir Res. 2007;8:18

62. de Torres JP, et al. Sex differences in mortality in patients with COPD. Eur Respir J. 2009;33(3):528-535.

63. Stolz D, et al. Differences in COPD Exacerbation Risk Between Women and Men: Analysis From the UK Clinical Practice Research Datalink Data. Chest. 2019;156(4):674-684.

64. Woodruff PG, et al. Clinical Significance of Symptoms in Smokers with Preserved Pulmonary Function. N Engl J Med. 2016;374(19):1811-1821.

65. Willis-Owen SAG, et al. COPD is accompanied by co-ordinated transcriptional perturbation in the quadriceps affecting the mitochondria and extracellular matrix. Sci Rep. 2018;8(1):12165.

66. He J, et al. Circulating Mitochondrial DAMPs Are Not Effective Inducers of Proteinuria and Kidney Injury in Rodents. PLoS One. 2015;10(4):e0124469.

67. van den Berge M, et al. Differential lung tissue gene expression in males and females: implications for the susceptibility to develop COPD. Eur Respir J. 2019;54(1):1702567.

68. Foreman MG, et al. Early-onset chronic obstructive pulmonary disease is associated with female sex, maternal factors, and African American race in the COPDGene Study. Am J Respir Crit Care Med. 2011;184(4):414-420.

69. Murray CJ, Lopez AD. Alternative projections of mortality and disability by cause 1990-2020: Global Burden of Disease Study. Lancet. 1997;349(9064):1498-1504

70. Martinez FJ, et al. Sex differences in severe pulmonary emphysema. Am J Respir Crit Care Med. 2007;176(3):243-252

71. Gan WQ, Man SF, Postma DS, Camp P, Sin DD. Female smokers beyond the perimenopausal period are at increased risk of chronic obstructive pulmonary disease: a systematic review and meta-analysis. Respir Res. 2006;7:52.

72. Sørheim IC, Johannessen A, Gulsvik A, Bakke PS, Silverman EK, DeMeo DL. Gender differences in COPD: are women more susceptible to smoking effects than men? Thorax. 2010;65(6):480-485

73. Silverman EK, et al. Gender-related differences in severe, early-onset chronic obstructive pulmonary disease. Am J Respir Crit Care Med. 2000;162(6):2152-2158.

74. Naz S, et al. Metabolomics analysis identifies sex-associated metabotypes of oxidative stress and the autotaxin-lysoPA axis in COPD. Eur Respir J. 2017;49(6):1602322.

75. de Torres JP, et al. Gender differences in plasma biomarker levels in a cohort of COPD patients: a pilot study. PLoS One. 2011;6(1):e16021

76. Kohler M, et al. Gender differences in the bronchoalveolar lavage cell proteome of patients with chronic obstructive pulmonary disease. J Allergy Clin Immunol. 2013;131(3):743-751.

77. Faner R, Gonzalez N, Cruz T, Kalko SG, Agustí A. Systemic inflammatory response to smoking in chronic obstructive pulmonary disease: evidence of a gender effect. PLoS One. 2014;9(5):e97491.

78. Jones B, et al. Animal models of COPD: What do they tell us? Respirology. 2017;22(1):21-32.

79. Johansson PI, et al. Plasma mitochondrial DNA and metabolomic alterations in severe critical illness. Crit Care. 2018;22(1):360.

80. Forbes GB, Bruining GJ. Urinary creatinine excretion and lean body mass. Am J Clin Nutr. 1976;29(12):1359-1366.

81. Gerchman F, et al. Body mass index is associated with increased creatinine clearance by a mechanism independent of body fat distribution. J Clin Endocrinol Metab. 2009;94(10):3781-3788.

82. Couper D, et al. Design of the Subpopulations and Intermediate Outcomes in COPD Study (SPIROMICS). Thorax. 2014;69(5):491-494

83. Galbán CJ, et al. Computed tomography-based biomarker provides unique signature for diagnosis of COPD phenotypes and disease progression. Nat Med. 2012;18(11):1711-1715.

84. R Core Team. R: A language and environment for statistical computing. https://www.R-project.org/. Accessed January 16, 2020

85. Wickham H. ggplot2: Elegant Graphics for Data Analysis. New York, NY: Springer-Verlag; 2009. 